\title{
Effect of Low-Dose Sodium Bicarbonate Supplementation on Intermittent Endurance Performance
}

\author{
Sakura Tanaka, Daichi Yamaguchi, Shoji Igawa \\ Department of Sport Science, College of Sport Sciences, Nippon Sport Science University, Kamoshida-Cho, Japan \\ Email: s.tanaka@nittai.ac.jp
}

How to cite this paper: Tanaka, S., Yamaguchi, D. and Igawa, S. (2018) Effect of Low-Dose Sodium Bicarbonate Supplementation on Intermittent Endurance Performance. Food and Nutrition Sciences, 9, 1316-1326.

https://doi.org/10.4236/fns.2018.911094

Received: October 25, 2018

Accepted: November 23, 2018

Published: November 26, 2018

Copyright $(0) 2018$ by authors and Scientific Research Publishing Inc. This work is licensed under the Creative Commons Attribution International License (CC BY 4.0).

http://creativecommons.org/licenses/by/4.0/

\begin{abstract}
In this study, we investigated the effect of sodium bicarbonate $\left(\mathrm{NaHCO}_{3}\right)$ supplementation at a dose of $0.2 \mathrm{~g} \cdot \mathrm{kg}^{-1} 40 \mathrm{~min}$ before an exercise on intermittent endurance performance and gastrointestinal distress. The participants were six healthy male students of a university. The Yo-Yo intermittent recovery test level 2 (Yo-Yo IR2) was used for the evaluation of intermittent endurance. The participants ingested water (Cont) or $\mathrm{NaHCO}_{3}$ independently at three timings. After drinking water, the Yo-Yo IR1 was performed for $2 \mathrm{~min}$ as warm-up. After resting for $5 \mathrm{~min}$, the Yo-Yo IR2 was initiated. The measurement items were exercise distance, nutrition intake, biochemical test results, and blood gas analysis findings. The participants who ingested $\mathrm{NaHCO}_{3}$ had a $14 \%$ extended distance than those who ingested Cont, and $2 / 3$ of those who took $\mathrm{NaHCO}_{3}$ showed a better motor performance. No significant difference was observed between the participants who took Cont and $\mathrm{NaHCO}_{3}$ in terms of $\mathrm{pH}$ level at baseline, and the $\mathrm{NaHCO}_{3}$ level was significantly higher during pre- and post-exercise $(\mathrm{p}<0.05)$. No significant difference was observed between the participants who took Cont and $\mathrm{NaHCO}_{3}$ in terms of bicarbonate ion level at baseline, and the $\mathrm{NaHCO}_{3}$ level was significantly higher during pre- and post-exercise $(\mathrm{p}<0.05)$. In conclusion, even when the participants ingested $\mathrm{NaHCO}_{3}$ at a low dose $\left(0.2 \mathrm{~g} \cdot \mathrm{kg}^{-1}\right)$, their exercise ability during an intermittent endurance test has improved. Furthermore, when digestive absorption is considered, eating a meal in advance may be able to suppress the onset of gastrointestinal distress.
\end{abstract}

\section{Keywords}

Sodium Bicarbonate, Yo-Yo IR2, Blood pH, High-Intensity Intermittent Endurance, Alkalosis 


\section{Introduction}

Since body fluids have a buffering capacity, the $\mathrm{pH}$ levels inside and outside the cells are maintained. When exercising, the $\mathrm{pH}$ level in the muscles and blood becomes acidic. This phenomenon is attributed to the production of lactic acid when glucose is converted into adenosine triphosphate (ATP) during exercise, and hydrogen ions $\left(\mathrm{H}^{+}\right)$that decompose from lactic acid accumulate in the body. It is a phenomenon that remarkably decreases the shrinkage and relaxation rates [1]. The intake of sodium bicarbonate $\left(\mathrm{NaHCO}_{3}\right)$ increases the $\mathrm{pH}$ level in the blood, and it regulates the speed in which the body becomes acidic during exercise. This phenomenon is attributed to the increase in bicarbonate ion $\left(\mathrm{HCO}_{3}^{-}\right)$ levels in the body owing to the outflow of $\mathrm{H}^{+}$to the outside of the cell and the buffering capacity that promotes neutralization. Moreover, recent studies have shown that $\mathrm{HCO}_{3}^{-}$may reduce the stimulation of sensory nerves by $\mathrm{H}^{+}$. Therefore, it may have a positive influence on the nervous and peripheral systems [2]. In relation to these facts, the intake of $\mathrm{NaHCO}_{3}$ increases the $\mathrm{pH}$ level in the blood to alkalinity and reduces fatigue. Bishop [3] has reported that female athletes who ingested $\mathrm{NaHCO}_{3}$ had a significantly high $\mathrm{NaHCO}_{3}$ level, which was measured using an ergometer, after an intermittent sprint test and that the intake of $\mathrm{NaHCO}_{3}$ improves intermittent sprint performance. In addition, the ingestion of $\mathrm{NaHCO}_{3}$ and intermittent exercise for $30 \mathrm{~min}$ resulted in an improved sprint performance in the early stage [4]. The improvements in performance occurred within 15 min of exercise, which is consistent with the time in which the $\mathrm{pH}$ of the blood rapidly changes. Several studies on the ergogenic effect of $\mathrm{NaHCO}_{3}$ uptake have been conducted. However, its intake dose and timing are not consistent. A dose of $0.3 \mathrm{~g} \cdot \mathrm{kg}^{-1}$ is frequently used [5]. This was obtained from several dose-response relationship studies. However, because $\mathrm{NaHCO}_{3}$ is $27 \%$ sodium, a dose of $0.3 \mathrm{~g} \cdot \mathrm{kg}^{-1}$ is significantly higher than the upper limit of $2300 \mathrm{mg} /$ day [6]. Therefore, substantial gastrointestinal distress, such as stomach pain and diarrhea, may highly occur [2] [7]. When using $\mathrm{NaHCO}_{3}$ in actual sports, it is important to take doses that do not cause gastrointestinal distress at ingestion timings that can maximize the effect. Siegler et al. [8] have reported that the timing of ingestion varies depending on its dose. When ingesting a dose of $0.3 \mathrm{~g} \cdot \mathrm{kg}^{-1}$, the blood $\mathrm{HCO}_{3}^{-}$concentration peaks at approximately $60 \mathrm{~min}$ after ingestion and peaks at around $40 \mathrm{~min}$ when ingesting a dose of $0.2 \mathrm{~g} \cdot \mathrm{kg}^{-1}$. It is preferred to start exercise when the $\mathrm{HCO}_{3}^{-}$concentration in the blood peaks because $\mathrm{HCO}_{3}^{-}$slows the speed in which the body becomes acidic. In this study, we investigated the effect of $\mathrm{NaHCO}_{3}$ intake $\left(0.2 \mathrm{~g} \cdot \mathrm{kg}^{-1}\right) 40$ min before an exercise on intermittent endurance performance and gastrointestinal distress.

\section{Methods}

\subsection{Participants}

The participants were six healthy male students of a university (age: $21.8 \pm 0.75$ years, height: $170.5 \pm 4.68 \mathrm{~cm}$, and weight: $68.0 \pm 9.25 \mathrm{~kg}$ ). After explaining to 
each participant the purpose and procedure of the research and the risks associated with the experiment, a written informed consent was obtained. This research was approved by the Ethics Review Committee of Nippon Sports Science University (no. 017 H 025).

\subsection{Method of Measurement}

The experiments were conducted twice at 1-week interval. In terms of food and drinks, caffeine and alcoholic beverages were banned on the day before and the day of the experiment, and the participants consumed the prescribed breakfast (200 $\mathrm{g}$ of white rice, 1 pack of natto, and miso soup) $3 \mathrm{~h}$ before the start of the trial. During the trial, we practiced twice on another day using the Yo-Yo intermittent recoverytest level2 (Yo-Yo IR2) to avoid differences in the proficiency of the participants. On the day of the experiment, they were visited $2 \mathrm{~h}$ before the start of the Yo-Yo IR2, and a blood sample was drawn (baseline information) while the participants were in supine position. While the participants were at rest in sitting position, they ingested water (Cont) or $\mathrm{NaHCO}_{3}$ independently at three timings. After drinking water, the Yo-Yo IR1 was performed for $2 \mathrm{~min}$ as warm-up. After resting for 5 min after warming-up, a blood sample was drawn (pre-exercise information), and the Yo-Yo IR2 test was initiated. Immediately after the end of the Yo-Yo IR2, blood was collected again (post-exercise information, Figure 1). Heart rate was measured continuously from the start of the Yo-Yo IR2 until $5 \mathrm{~min}$ after the end of the test exercise. The blood lactic concentration was set just before the Yo-Yo IR2 $(160 \mathrm{~m}, 280 \mathrm{~m}$, and $440 \mathrm{~m})$, immediately after termination, 1 min after completion, and 3, 5, and 10 min after.

\subsection{Yo-Yo IR2}

The Yo-Yo IR2 is based on the shuttle run test in which a marker is placed $5 \mathrm{~m}$ behind the start/goal line, and a participant jogs around this $5-\mathrm{m}$ section and returns to the line (Figure 2). The jogging time is $10 \mathrm{~s}$. If it is recorded every roundtrip $(40 \mathrm{~m})$ and the participant cannot return to the start/goal line within the time, warning is provided during the first occurrence, and the lap was recorded at the stage when a participant could not return to the second time. In addition, level 2 focuses on high-intensity intermittent motion combined with anaerobic and aerobic exercise [9].

\subsection{Intake Conditions}

In total, $200 \mathrm{~mL}$ of Cont or $\mathrm{NaHCO}_{3}$ was consumed per intake. The ingestion timing was 3 times in total ( $1 \mathrm{~h}, 40 \mathrm{~min}$, and $20 \mathrm{~min}$ before starting the exercise). The participants ingested $\mathrm{NaHCO}_{3} 40$ min before the exercise. The amount of ingested $\mathrm{NaHCO}_{3}$ was $0.2 \mathrm{~g} \cdot \mathrm{kg}^{-1}$ body weight, and $200 \mathrm{ml}$ of Cont was ingested.

\subsection{Nutrition Intake Survey}

A survey on food intake was conducted the day before the experiment using both self-recorded food intake and visual records obtained using the provided 

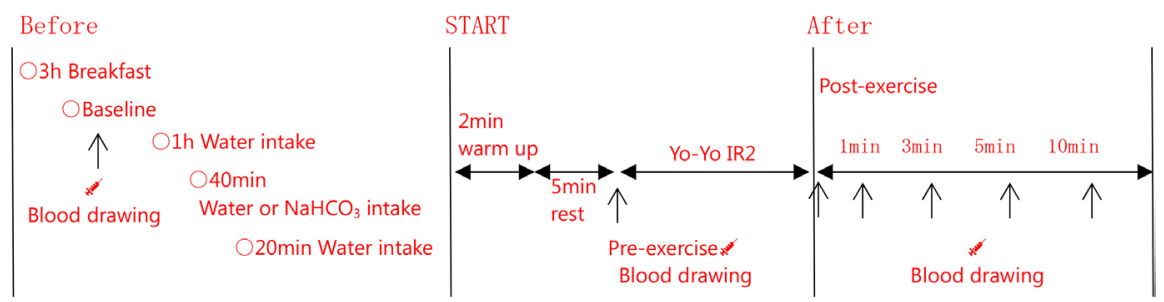

Figure 1. Experiment protocol.

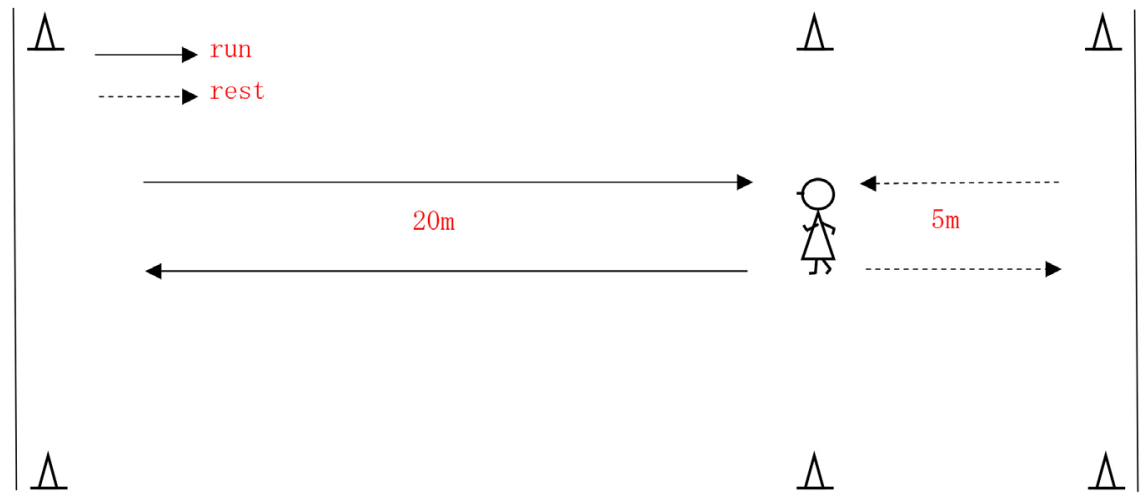

Figure 2. Yo-Yo IR2 protocol.

digital camera. The nutrient intake of the participants was calculated based on the diet record and photographs. All dietary records were used to determine total energy intake and amount of carbohydrate, protein, and lipid intake with a computerized nutrient analysis program (Excel Eiyokun version 8.0, Japan Food Composition Table version 5, Kenpakusya, Tokyo, Japan). Total energy intake and amount of carbohydrate, protein, and lipid in take from commercially prepared and restaurant food were calculated using information from the manufacturer's websites or by asking the manufacturer.

\subsection{Biochemical Test and Blood Gas Analysis}

Blood was collected from the cephalic vein. After standing for $2 \mathrm{~h}$, the serum was collected by centrifugation at $3000 \mathrm{rpm}$ for $5 \mathrm{~min}$ using a centrifugal separator. Analysis items included total protein (TP), albumin (Alb), creatine kinase (CK), triglyceride (TG), and blood urea nitrogen (BUN) levels. BML Co., Ltd. conducted the analysis (Tokyo, Japan).

For blood gas analysis, a blood gas analyzer (Rapid Labo 348 EX, Siemens) was used. The collected blood was quickly set in the instrument, and analysis was started. The analysis items were $\mathrm{pH}$, sodium $\left(\mathrm{Na}^{+}\right)$, potassium $\left(\mathrm{K}^{+}\right)$, and bicarbonate ion $\left(\mathrm{HCO}_{3}^{-}\right)$levels.

\subsection{Analysis}

The Statistical Package for the Social Sciences software version 22 (IBM Inc.) was used for analysis. All data were expressed as mean \pm standard deviation 
(mean $\pm \mathrm{SD}$ ). A $t$ test with correspondence between beverages was conducted, and one-way analysis of variance was carried out for the variation between beverages. The Tukey's HSD method was used, and significant differences were observed. The significance level was set at $\mathrm{p}<0.05$.

\section{Results}

A significant difference was observed in the $\mathrm{NaHCO}_{3}$ level as well as total energy and carbohydrate intake ( $\mathrm{p}<0.05$, Table 1$)$. No significant differences were noted in the protein and lipid intake. Moreover, the distance of exercise between the participants who ingested Cont and $\mathrm{NaHCO}_{3}$ did not significantly differ (Figure 3). However, the intake of $\mathrm{NaHCO}_{3}$ resulted in $14 \%$ extended distance, and $2 / 3$ of the participants who took $\mathrm{NaHCO}_{3}$ had a better motor performance. Heart rate and blood lactate concentration are shown in Table 2. Heart rate gradually increased from the start of the Yo-Yo IR2. However, no significant difference was found in terms of Cont and $\mathrm{NaHCO}_{3}$ intake. Moreover, the participants who ingested Cont and $\mathrm{NaHCO}_{3}$ did not significantly differ in terms of blood lactate concentration at baseline and during pre- and post-exercise. However, the $\mathrm{NaHCO}_{3}$ level was significantly elevated at 3 and $5 \mathrm{~min}$ after the end of the Yo-Yo IR2 ( $\mathrm{p}<0.05)$. Furthermore, the $\mathrm{NaHCO}_{3}$ level was significantly higher in the peak blood lactic concentration $(\mathrm{p}<0.05)$. Results of the biochemical tests are presented in Table 3. No significant difference was observed between the participants who took Cont and $\mathrm{NaHCO}_{3}$ in the fluctuation of all items at baseline and during pre- and post-exercise. In addition, the participants who took Cont and $\mathrm{NaHCO}_{3}$ did not significantly differ in terms of TP, Alb, CK, TG, and BUN levels. Results of the blood gas analysis are presented in Figure 4 and Table 4. No significant difference was observed between the participants who took Cont and $\mathrm{NaHCO}_{3}$ in terms of $\mathrm{pH}$ at baseline, and the $\mathrm{NaHCO}_{3}$ level was significantly higher during pre-and post-exercise $(\mathrm{p}<0.05)$. No significant difference was observed between the participants who took Cont and $\mathrm{NaHCO}_{3}$ in terms of $\mathrm{HCO}_{3}^{-}$level at baseline, and the $\mathrm{NaHCO}_{3}$ level was significantly higher during pre-and post-exercise $(\mathrm{p}<0.05) . \mathrm{Na}^{+}$level was significantly higher in participants who took $\mathrm{NaHCO}_{3}$ than those who took Cont during pre- and post-exercise $(\mathrm{p}<0.05)$. No significant difference was observed in the $\mathrm{K}^{+}$level of the participants who took Cont and $\mathrm{NaHCO}_{3}$.

Table 1. Nutritional intake a day before the experiment.

\begin{tabular}{ccccc}
\hline & \multicolumn{2}{c}{ Cont } & \multicolumn{2}{c}{$\mathrm{NaHCO}_{3}$} \\
\cline { 2 - 5 } & Mean & SD & Mean & SD \\
\hline Total energy intake (kcal) & 1884.8 & 661.6 & $1013.2^{*}$ & $413.9^{*}$ \\
Carbohydrate (g) & 276.5 & 106.3 & $133.3^{*}$ & $86.6^{*}$ \\
Protein (g) & 67.4 & 28.9 & 37.7 & 18.1 \\
Lipid (g) & 49.2 & 24.5 & 33.1 & 19.7 \\
\hline
\end{tabular}

Values were presented as mean $\pm \mathrm{SD}$. ${ }^{\star} \mathrm{p}<0.05$ vs. Cont. Cont: water. 
Table 2. Yo-Yo IR2. Variations in heart rate and blood lactate concentrations during post-exercise.

\begin{tabular}{ccccc}
\hline & \multicolumn{2}{c}{ Cont } & \multicolumn{2}{c}{$\mathrm{NaHCO}_{3}$} \\
\cline { 2 - 5 } & Mean & SD & Mean & SD \\
\hline Heart rate $(\mathrm{bpm})$ & 179.8 & 9.8 & 177.3 & 13.0 \\
Blood lactic concentration $(\mathrm{mmol} / \mathrm{L})$ & & & \\
Pre-exercise & 1.3 & 0.3 & 1.5 & 0.4 \\
Post-exercise & 9.9 & 3.4 & 11.4 & 3.0 \\
After 1 minute & 10.6 & 0.7 & 11.4 & 2.3 \\
After 3 minutes & 10.8 & 1.9 & $13.4^{*}$ & 2.5 \\
After 5 minutes & 11.0 & 1.4 & $14.4^{*}$ & 2.6 \\
After 10 minutes & 10.9 & 1.9 & 12.8 & 2.4 \\
\hline
\end{tabular}

Values were presented as mean $\pm \mathrm{SD} .{ }^{*} \mathrm{p}<0.05$ vs. Cont.

Table 3. Biochemical test results.

\begin{tabular}{ccccccc}
\hline & \multicolumn{3}{c}{ Cont } & \multicolumn{3}{c}{$\mathrm{NaHCO}_{3}$} \\
\cline { 2 - 6 } & Baseline & Pre-exercise & Post-exercise & Baseline & Pre-exercise & Post-exercise \\
\hline TP (g/dL) & $7.2 \pm 0.5$ & $7.2 \pm 0.4$ & $7.9 \pm 0.3$ & $7.0 \pm 0.8$ & $7.1 \pm 0.2$ & $7.7 \pm 8.2$ \\
Alb (g/dL) & $4.4 \pm 0.3$ & $4.3 \pm 0.2$ & $4.7 \pm 0.2$ & $4.2 \pm 0.2$ & $4.3 \pm 0.2$ & $4.8 \pm 0.3$ \\
CK (U/L) & $198.1 \pm 110.3$ & $202.8 \pm 118.6$ & $225.0 \pm 122.1$ & $228.1 \pm 109.5$ & $232.1 \pm 107.7252 .5 \pm 111.7$ \\
TG (mg/dL) & $101.6 \pm 66.7$ & $102.6 \pm 69.5$ & $116.5 \pm 83.4$ & $105.3 \pm 54.9$ & $100.0 \pm 70.7$ & $113.0 \pm 83.2$ \\
BUN (mg/dL) & $13.9 \pm 3.8$ & $13.6 \pm 3.4$ & $13.6 \pm 3.5$ & $12.8 \pm 1.8$ & $12.7 \pm 1.8$ & $12.8 \pm 1.9$ \\
\hline
\end{tabular}

Values were presented as mean $\pm \mathrm{SD} .{ }^{\star} \mathrm{p}<0.05$ vs. Con.

Table 4. $\mathrm{Na}^{+}$and $\mathrm{K}^{+}$levels.

\begin{tabular}{|c|c|c|c|c|c|c|}
\hline & \multicolumn{3}{|c|}{ Cont } & \multicolumn{3}{|c|}{$\mathrm{NaHCO}_{3}$} \\
\hline & Baseline & Pre-exercise & Post-exercise & Baseline & Pre-exercise & Post-exercise \\
\hline $\mathrm{Na}^{+}(\mathrm{mmol} / \mathrm{L})$ & $142.3 \pm 1.2$ & $143.2 \pm 1.0$ & $148.1 \pm 1.7$ & $142.8 \pm 1.2$ & $144.8 \pm 1.3^{*}$ & $149.3 \pm 1.2^{*}$ \\
\hline $\mathrm{K}^{+}(\mathrm{mmol} / \mathrm{L})$ & $4.3 \pm 0.7$ & $5.9 \pm 1.4$ & $6.7 \pm 1.4$ & $3.9 \pm 0.1$ & $4.7 \pm 1.3$ & $5.3 \pm 0.9$ \\
\hline
\end{tabular}

Values were presented as mean $\pm \mathrm{SD} .{ }^{*} \mathrm{p}<0.05$ vs. Cont.

\section{Discussion}

In the Yo-Yo IR2, the intake of $\mathrm{NaHCO}_{3}$ compared with Context ended the exercise distance by $14 \%$. Krustrup et al. [10] have shown that the ingestion of 0.4 $\mathrm{g} \cdot \mathrm{kg}^{-1}$ of $\mathrm{NaHCO}_{3}$ extended the distance by $14 \%$ when the same exercise was performed. In addition, Jason [11] et al. have presented that a distance extension of $12.4 \%$ was observed when $0.3 \mathrm{~g}$ of $\mathrm{NaHCO}_{3}$ was ingested prior to the same exercise. These previous studies have shown the ergogenic effect of $\mathrm{NaHCO}_{3}$ on high-intensity exercise state, which allows the performance of short-term, intermittent and anaerobic Yo-Yo IR2 under metabolic stress. One of the reasons for improving the capacity of intermittent exercise is the increase in $\mathrm{pH}$ due to 


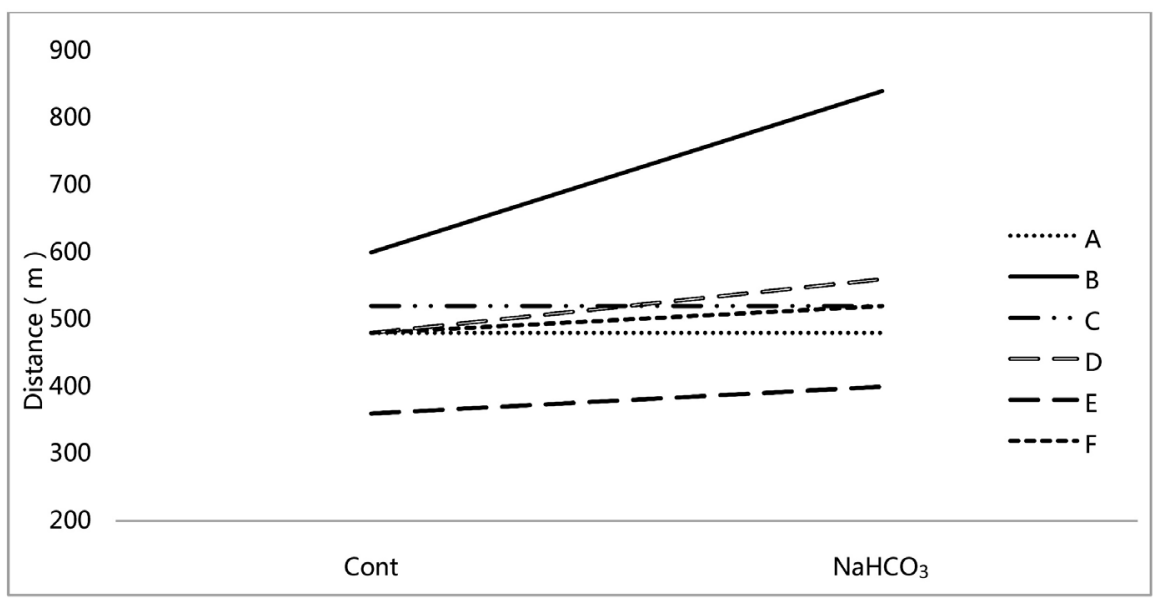

Figure 3. Distance of exercise in Yo-Yo IR2.

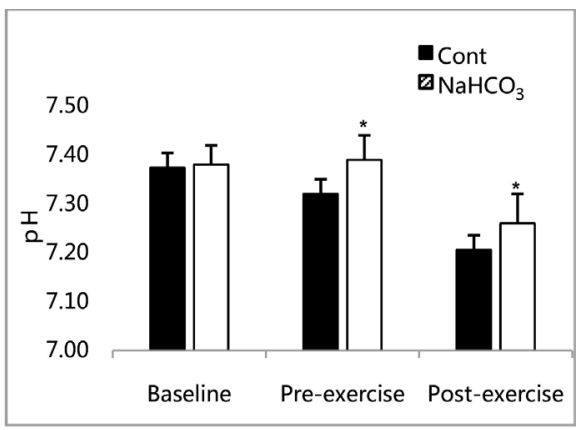

(a)

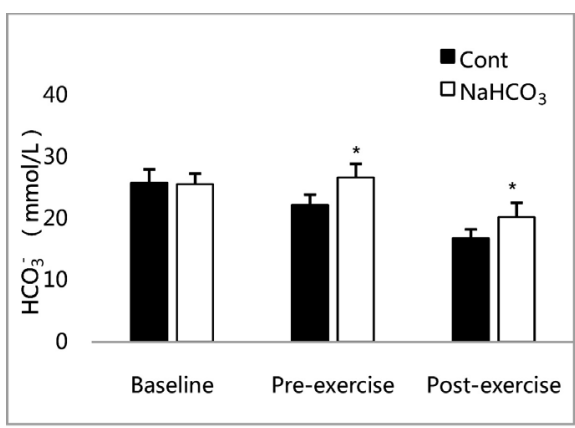

(b)

Figure 4. $\mathrm{pH}$ (a)and $\mathrm{HCO}_{3}^{-}$(b) ${ }^{\star} \mathrm{p}<0.05$ vs. Cont.

an elevated buffering capacity in the blood by $\mathrm{HCO}_{3}^{-}$, and the $\mathrm{H}^{+}$value and lactate gradient of the muscle and blood are increased [12]. In this study, the $\mathrm{HCO}_{3}^{-}$level was significantly elevated by $20 \%$ during pre-exercise when $\mathrm{NaH}-$ $\mathrm{CO}_{3}$ was ingested. In addition, at baseline, the $\mathrm{pH}$ levels of the participants were $7.37 \pm 0.03$ after ingesting Cont and $7.38 \pm 0.05$ after ingesting $\mathrm{NaHCO}_{3}$. However, $1 \mathrm{~h}$ after the intake of Cont and $\mathrm{NaHCO}_{3}$, the $\mathrm{pH}$ levels were $7.32 \pm 0.03$ and $7.39 \pm 0.05$, respectively. Only $\mathrm{NaHCO}_{3}$ was likely to increase $\mathrm{pH}$ level to alkalinity. Despite the fact that the blood collection timing during pre-exercise was after warm-up, the $\mathrm{pH}$ level of the participants who took $\mathrm{NaHCO}_{3}$ was more alkaline than the baseline. In addition, despite the increased exercise distance after ingesting $\mathrm{NaHCO}_{3}$ compared to Cont, $\mathrm{NaHCO}_{3}$ significantly increases the $\mathrm{pH}$ and $\mathrm{HCO}_{3}^{-}$levels during post-exercise. These may have increased the movement distance by activating the buffering capacity in the blood. Significantly higher $\mathrm{Na}^{+}$values were observed during pre- and post-exercise after the ingestion of $\mathrm{NaHCO}_{3}$. No significant difference was observed in $\mathrm{K}^{+}$level. However, it was more likely lower during pre- and post-exercise after the ingestion of $\mathrm{NaHCO}_{3}$. The $\mathrm{pH}$ level during pre-exercise was significantly higher in participants who ingested $\mathrm{NaHCO}_{3}$ than in those who ingested Cont. In terms of $\mathrm{K}^{+}$ level, no significant difference was observed, and a decrease may be observed. 
Thus, the patients were already in an alkalosis state before warming-up. During fatigue after performing the Yo-Yo IR2, the $\mathrm{pH}$ and $\mathrm{HCO}_{3}^{-}$levels increased. The onset of fatigue during high-intensity intermittent exercise can be caused by the intricate interactions between intracellular and extracellular concentrations and ion gradients, such as $\mathrm{K}^{+}, \mathrm{Na}^{+}$, and $\mathrm{H}^{+}$[13] [14]. A high $\mathrm{Na}^{+}$level may increase the possibility of $\mathrm{H}^{+}$outflow from inside the muscle during exercise. However, the potential fatigue effects of homeostatic imbalances on these ions are exerted in the muscle stroma compared to the intracellular environment. In this study, blood gas measurements are not performed during the Yo-Yo IR2. However, the interactions with ion gradients may have appeared after performing the Yo-Yo IR2. Sostaric et al. [15] have shown an improved exercise capacity after $\mathrm{NaHCO}_{3}$ supplementation. The intake of $\mathrm{NaHCO}_{3}$ inhibits the increase in $\mathrm{K}^{+}$level in the muscle stroma that occurs during the intense contractile activity of the muscles, and it may attenuate the degree of $\mathrm{K}^{+}$-induced inactivation of myocytes during this activity [16] [17]. Furthermore, the increase in blood $\mathrm{pH}$ improves high-intensity intermittent endurance [18]. This phenomenon is attributed to the re-synthesis of creatine phosphate (ATP) that depends on the transport of $\mathrm{H}^{+}$from the cell and intramuscular $\mathrm{pH}$, and as a result, the re-synthesis of ATP improves when the $\mathrm{pH}$ level is alkaline. Therefore, the production of more energy is possible. We believe that the same phenomenon was observed in this research and the performance of the participants may be affected.

Bangsbo et al. [9] have shown that blood lactate after the performance of the Yo-Yo IR2 test reached its peak during the recovery period of 5 - $8 \mathrm{~min}$. The intake of $\mathrm{NaHCO}_{3}$ promotes metabolite translocation. $\mathrm{NaHCO}_{3}$ is divided into $\mathrm{Na}^{+}$ and $\mathrm{HCO}_{3}^{-}$in the blood, and $\mathrm{HCO}_{3}^{-}$is bound to $\mathrm{H}^{+}$to adjust the $\mathrm{pH}$ of the blood. By contrast, $\mathrm{Na}^{+}$binds to the remaining constituents dissociated from $\mathrm{H}^{+}$ and simultaneously produces sodium lactate. When improving the performance of lactic acid produced in large quantities via exercise, the recovery of lactic acid in the blood is essential. In this study, the peak of blood lactic acid was reached after 5 min of recovery. Moreover, Marriott et al. [12] have shown that $\mathrm{NaHCO}_{3}$ resulted in a higher glycolytic contribution and undesirable intramuscular lactate production compared to caffeine and placebo. In this study, it was predicted that anaerobic energy metabolism was actively carried out at the time of $\mathrm{NaH}$ $\mathrm{CO}_{3}$ intake, which may also be related to longer exercise distance. In this study, although the total energy and carbohydrate intakes significantly increased than the $\mathrm{NaHCO}_{3}$ and Cont intakes on the previous day, the distance of exercise was increased after $\mathrm{NaHCO}_{3}$ supplementation. This result suggests that the use of carbohydrate as energy during glycolysis is more effective than ingesting $\mathrm{NaH}$ $\mathrm{CO}_{3}$.

Several previous studies have shown that metabolic alkalosis was caused by ingesting high doses of $\mathrm{NaHCO}_{3}\left(0.3-0.4 \mathrm{~g} \cdot \mathrm{kg}^{-1}\right.$ body weight $)$ after fasting. However, the high capacity intake of $\mathrm{NaHCO}_{3}$ causes gastrointestinal distress, such as diarrhea due to osmotic pressure. Naughton [19] has shown that the 
performance does not improve further even if the dose of bicarbonate exceeds $0.3 \mathrm{~g} \cdot \mathrm{kg}^{-1}$. However, it causes serious side effects. In addition, Carr [7] has reported that the optimal intake of $\mathrm{NaHCO}_{3}$ is less likely to cause gastrointestinal distress when meals are also taken [20]. In the present study, by feeding meals 3 $\mathrm{h}$ before the start of the Yo-Yo IR2 test, gastrointestinal pain was prevented, and based on the self-reports of the participants, they did not develop stomach pain. Furthermore, according to the study by Siegler [8] et al., the minimum capacity causing metabolic alkalosis is $0.2 \mathrm{~g} \cdot \mathrm{kg}^{-1}$. Bishop et al. [3] have reported that a significant improvement was observed in the intermittent endurance test compared with the placebo with an ingestion of $0.2 \mathrm{~g}^{\mathrm{kg}} \mathrm{kg}^{-1}$ of $\mathrm{NaHCO}_{3}$. In the present study, similar results were obtained, indicating that the intake of $0.2 \mathrm{~g} \cdot \mathrm{kg}^{-1}$ of $\mathrm{NaHCO}_{3}$ has effects on intermittent endurance test. In addition, the risk of developing gastrointestinal distress can be alleviated by taking a meal in advance. In this study, $\mathrm{NaHCO}_{3}$ was difficult to ingest in capsules. Thus, it was dissolved in water and ingested. In relation to this, it differed in taste; thus, we did not use the placebo. Because the difference in taste was obvious, the placebo was not used. Therefore, the effect of the placebo may have affected the outcome.

\section{Conclusion}

In this study, we investigated the influence of $\mathrm{NaHCO}_{3}$ uptake $\left(0.2 \mathrm{~g} \cdot \mathrm{kg}^{-1}\right) 40$ min before an intermittent exercise on endurance performance and gastrointestinal distress. In conclusion, even at a low dose of $0.2 \mathrm{~g} \cdot \mathrm{kg}^{-1}$, the exercise ability of the participants during an intermittent endurance test has improved. Furthermore, when digestive absorption is considered, eating a meal in advance may be able to suppress the onset of gastrointestinal distress.

\section{Conflicts of Interest}

The authors declare no conflicts of interest regarding the publication of this paper.

\section{References}

[1] Wada, M., Mishima, T. and Yamada, T. (2006) The Role of Lactic Acid in Muscle Contraction. JOPER, 51, 229-239.

[2] McNaughton, L.R., Gough, L., Deb, S., Bentley, D. and Sparks, S.A. (2016) Recent Developments in the Use of Sodium Bicarbonate as an Ergogenic Aid. Current Sports Medicine Reports, 15, 233-244.

[3] Bishop, D. and Claudius, B. (2005) Effects of Induced Metabolic Alkalosis on Prolonged Intermittent-Sprint Performance. Medicine \& Science in Sports \& Exercise, 37, 759-767. https://doi.org/10.1249/01.MSS.0000161803.44656.3C

[4] Price, M.J. and Simons, C. (2010) The Effect of Sodium Bicarbonate Ingestion on High-Intensity Intermittent Running and Subsequent Performance. Journal of Strength and Conditioning Research, 24, 1834-1842. https://doi.org/10.1519/JSC.0b013e3181e06e4a

[5] Burke, L.M. (2013) Practical Considerations for Bicarbonate Loading and Sports Performance. Nestlé Nutrition Institute Workshop Ser, 75, 15-26.

https://doi.org/10.1159/000345814 
[6] Kahle, L.E., Kelly, P.V., Eliot, K.A. and Weiss, E.P. (2013) Acute Sodium Bicarbonate Loading Has Negligible Effects on Resting and Exercise Blood Pressure But Causes Gastrointestinal Distress. Nutrition Research, 33, 479-486. https://doi.org/10.1016/j.nutres.2013.04.009

[7] Carr, A.J., Slater, G.J., Gore, C.J., Dawson, B. and Burke, L.M. (2011) Effect of Sodium Bicarbonate on $\mathrm{HCO}_{3}^{-}, \mathrm{pH}$, and Gastrointestinal Symptoms. International Journal of Sport Nutrition and Exercise Metabolism, 21, 189-194. https://doi.org/10.1123/ijsnem.21.3.189

[8] Siegler, J.C., Midgley, A.W., Polman, R.C. and Lever, R. (2010) Effects of Various Sodium Bicarbonate Loading Protocols on the Time-Dependent Extracellular Buffering Profile. Journal of Strength and Conditioning Research, 24, 2551-2557. https://doi.org/10.1519/JSC.0b013e3181aeb154

[9] Bangsbo, J., Iaia, F.M. and Krustrup, P. (2008) The Yo-Yo Intermittent Recovery Test: A Useful Tool for Evaluation of Physical Performance in Intermittent Sports. Sports Medicine, 38, 37-51. https://doi.org/10.2165/00007256-200838010-00004

[10] Krustrup, P., Ermidis, G. and Mohr, M. (2015) Sodium Bicarbonate Intake Improves High-Intensity Intermittent Exercise Performance in Trained Young Men. Journal of the International Society of Sports Nutrition, 12, 25. https://doi.org/10.1186/s12970-015-0087-6

[11] Cholewa, J.M., Grannis, D.J., Jaffe, D.A., Guimarães-Ferreira, L., Matthews, T.D. and Paolone, V.J. (2015) The Effects of Sodium Bicarbonate Supplementation on a Soccer Specific Conditioning Test in Division III Soccer Players. Journal of Trainology, 4, 19-24.

[12] Marriott, M., Krustrup, P. and Mohr, M. (2015) Ergogenic Effects of Caffeine and Sodium Bicarbonate Supplementation on Intermittent Exercise Performance Preceded by Intense Arm Cranking Exercise. Journal of the International Society of Sports Nutrition, 12, 13. https://doi.org/10.1186/s12970-015-0075-X

[13] McKenna, M.J., Bangsbo, J. and Renaud, J.M. (1985) Muscle $\mathrm{K}^{+}, \mathrm{Na}^{+}$, and Cl Disturbances and $\mathrm{Na}^{+}-\mathrm{K}^{+}$Pump Inactivation: Implications for Fatigue. Journal of $\mathrm{Ap}$ plied Physiology, 104, 288-295. https://doi.org/10.1152/japplphysiol.01037.2007

[14] Cairns, S.P. and Lindinger, M.I. (2008) Do Multiple Ionic Interactions Contribute to Skeletal Muscle Fatigue? Journal of Physiology, 586, 4039-4054.

https://doi.org/10.1113/jphysiol.2008.155424

[15] Sostaric, S.M., Skinner, S.L., Brown, M.J., Sangkabutra, T., Medved, I., Medley, T., Selig, S.E., Fairweather, I., Rutar, D. and McKenna, M.J. (2006) Alkalosis Increases Muscle $\mathrm{K}^{+}$Release, But Lowers Plasma $\mathrm{K}^{+}$and Delays Fatigue during Dynamic Forearm Exercise. Journal of Physiology, 570, 185-205.

https://doi.org/10.1113/jphysiol.2005.094615

[16] Overgaard, K., Højfeldt, G.W. and Nielsen, O.B. (2010) Effects of Acidification and Increased Extracellular Potassium on Dynamic Muscle Contractions in Isolated Rat Muscles. Journal of Physiology, 588, 5065-5076. https://doi.org/10.1113/jphysiol.2010.195727

[17] Street, D., Nielsen. J.J., Bangsbo, J. and Juel, C. (2015) Metabolic Alkalosis Reduces Exercise-Induced Acidosis and Potassium Accumulation in Human Skeletal Muscle Interstitium. Journal of Physiology, 566, 481-489. https://doi.org/10.1113/jphysiol.2005.086801

[18] Costill, D.L., Verstappen, F., Kuipers, H., Janssen, E. and Fink, W. (1984) Acid-Base Balance during Repeated Bouts of Exercise: Influence of $\mathrm{HCO}_{3}$. International Journal of Sports Medicine, 5, 228-231. https://doi.org/10.1055/s-2008-1025910 
[19] McNaughton, L.R. (1992) Bicarbonate Ingestion: Effects of Dosage on 60 s Cycle Ergometry. Journal of Sports Sciences, 10, 415-423.

https://doi.org/10.1080/02640419208729940

[20] Peeling, P., Binnie, M.J., Goods, P.S.R., Sim, M. and Burke, L.M. (2018) Evidence-Based Supplements for the Enhancement of Athletic Performance. International Journal of Sport Nutrition and Exercise Metabolism, 28, 178-187.

https://doi.org/10.1123/ijsnem.2017-0343 